\title{
Editorial
}

\section{Alveolar response to injury}

Injury to the cells of the gas exchanging surface of the lung is an unusual event considering the continuing barrage of inhaled irritants and blood-borne chemicals coped with daily. The innate efficiency of the mucociliary and macrophagic systems that keep the alveoli clean and of the detoxifying mechanisms that protect the alveolar capillaries from damage is impressive and cellular stability in the gas exchanging units is reflected in the very slow turnover rate, some four to six weeks, of the alveolar epithelium compared to the cells of the airways which have a lifespan of a few days only. ${ }^{1}$ Normally, there is little cellular loss within the alveoli and small need for replacement but, like the liver, the reparative potential of the alveolar cells is great and under most circumstances injury is followed rapidly by cellular regeneration with restoration of normal function. The maintenance of a stable milieu within the alveoli is dependent upon an effective interplay of macrophages, epithelial-endothelial lining cells and the miscellany of cellular elements that constitutes the pulmonary interstitium. The interdependence of these phagocytic, gas transporting, and supportive cells is manifest in their different susceptibilities to injury and in their complex interactions during repair and regeneration.

The cells that line the air-blood barrier are exquisitely adapted to their functions of gas exchange and of providing an effective barrier against the leakage of plasma constituents into the alveoli. Further, these cells react speedily to repair breaches in the wall. This delicate structural compromise between the opposing needs of a thin gas-exchanging membrane and a tight defensive barrier has not been achieved without cost however. The cells most susceptible to almost all forms of air-borne or blood-borne injury are the type 1 epithelial cells, which present a huge surface area to the atmosphere, and the endothelial cells lining the intricate vascular network of the lung. In contrast the large type 2 cells, specifically programmed for the secretion of surfactant, are considerably less vulnerable to injury. These cells constitute the reserve population which, given an appropriate stimulus, replicates and repopulates an injured alveolus. This pattern of differential susceptibility is pivotal to an understanding of alveolar responses to injury.

Address for reprint requests: Professor DH Bowden, Department of Pathology, University of Manitoba, 770 Bannatyne Avenue, Winnipeg, Canada R3E OW3.
Endothelial cells are the most numerous of pulmonary cells accounting for almost $40 \%$ of the total. ${ }^{2}$ They represent a constantly renewing population, with a daily turnover rate somewhat less than $1 \%$ of their total number. ${ }^{3}$ The majority of endothelial cells in the lung line thin-walled blood vessels and capillaries; consequently they are vulnerable to attack from two directions-from the blood stream and by diffusion of gases across the air-blood membrane. Vascular endothelium in general has an immense capacity for regeneration and this certainly holds for the pulmonary endothelium. Acute injury is followed by a burst of proliferative activity-for example, in the recovery period after oxygen poisoning as many as $8 \%$ of pulmonary cells are actively synthesising DNA at any one time and, of these, at least $50 \%$ are endothelial. ${ }^{4}$

The speed of endothelial regeneration after focal injuries effectively seals the gaps and in most instances repair is uneventful. Some degree of platelet adherence is inevitable but the majority of these micro-thrombi are lysed and endothelial repair proceeds without hindrance. More severe damage to the vascular lining, with stripping of endothelium and bareing of the underlying collagenous matrix, carries with it the danger of extensive platelet adherence with consequent thrombosis and vascular occlusion. This sequence is of particular interest and import in the development of radiation induced fibrosis which is a direct consequence of vascular injury. ${ }^{5}$

Pulmonary epithelial cells are not equally susceptible to injury. Anatomically, the centriacinar regions are particularly vulnerable to toxic gases and, within these areas, the ciliated bronchiolar cell and the type 1 alveolar cell are more readily damaged than the non-ciliated Clara cell and the surfactant secreting type 2 cell. The alveolar epithelial cells, in common with all lining cells, constitute a renewing population and, of these cells, only the type 2 cell divides. The gas-exchanging type 1 cell does not enter the mitotic cycle. ${ }^{6}$ The seeming paradox of an apparently simple cell incapable of division is readily understood in the context of alveolar development during intrauterine life. The primitive cuboidal epithelium, invading the mesenchyme to form the bronchial tree and the terminal air sacs, progressively differentiates to form type 2 cells and, as term approaches, the majority of these cells further differentiate to squamous type 1 cells which overlie the capillaries.? 
The type 1 cell, specifically designed for gaseous transfer, is incapable of division whereas the type 2 cell, although functionally a secretory cell, retains its fetal potential for division and subsequent differentiation to form thin gas-exchanging cells. Viewed in this light, cellular regeneration after alveolar injury may be regarded as a recapitulation of fetal development.

The response of type 1 cells to injury by agents as diverse as viruses, oxidant gases, irradiation, and blood-borne drugs is similar, the results being largely dependent upon the dosage and the duration of the insult. The endothelial component of the air-blood barrier responds to injury by leaking fluid and protein into the pulmonary interstitium. On the other side of the barrier, epithelial cells united by tight junctions provide a formidable barrier to further egress of this interstitial exudate. Extensive destruction of type 1 epithelium, the main component of the alveolar lining, is therefore a catastrophic event since it allows plasma to flow without impediment into the air sacs. This is the morphological basis for the formation of hyaline membranes. The occurrence of these membranes in a variety of conditions such as viral pneumonias, irradiation, oxygen poisoning, and adult and infantile types of the respiratory distress syndrome points to a common denominator, multifocal necrosis of type 1 cells with loss of fibrin-containing plasma into the terminal air spaces.

Necrosis of type 1 alveolar cells triggers mitotic division of adjacent type 2 cells. These new cells temporarily repopulate the damaged alveolar wall and subsequently transform to functional gasexchanging type 1 cells. ${ }^{8}$ The rapidity of these changes may be gauged from the turnover time of the type 2 cells in the reparative phase when the total population may be replicated in three days. ${ }^{9}$

The usual process of epithelial repair ensures return to the normal thin air-blood barrier. This is exemplified in murine oxygen toxicity; the majority of animals die with solid lungs and hyaline membranes but those which survive make a complete recovery. It is reasonable to presume the same sequence in patients with acute alveolar injury. With the increasing use of assisted ventilation many more patients now survive the severe episodes of hypoxia and recover completely; some, albeit a small number, survive only to develop fibrosis and restrictive lung disease. Little is known about the pathogenesis of this process; of interest, however, is the almost invariable concurrence of interstitial fibrosis with large numbers of type 2 epithelial cells lining the affected alveoli. ${ }^{10}$ This association suggests that the development of fibrosis may be related in some way to disruption of the normal relationships and channels of communication between epidermal and endothelial lining cells and the supporting or mesenchymal cells of the pulmonary interstitium. The cells do not exist in isolation and their responses to injury are interdependent also.

Pulmonary injury and repair inevitably involves interactions between epithelial, endothelial, and mesenchymal cells. Conditions which delay the orderly process of regeneration or disturb the $\overrightarrow{\vec{J}}$ continuity of interplay between alveolar cells $\omega$ predispose to the development of pulmonary fibrosis. Such a sequence is observed in several experimental $x$ models of lung injury; the delay of epithelial o. regeneration found in severe oxygen-induced damage $\vec{\overrightarrow{ }}$ allows untrammelled proliferation of interstitial o fibroblasts. ${ }^{11}$ Similarly, injury induced by the anticancer drug bleomycin is followed by abnormal 윽 repair. In the latter instance, the drug produces DNA scission in dividing type 2 cells with the induction of $z$ abnormal progeny, monstrous giant cells, and $\underset{\Phi}{ }$ inappropriate ciliated cells within air sacs. This disruption of the normal sequence of repair is $\underset{\mathbb{D}}{ }$ invariably accompanied by fibrosis. On the other side $\vec{\oplus}$ of the air-blood barrier delayed regeneration of $\stackrel{\infty}{\rightarrow}$ endothelial cells after injury induced by irradiation or butylated hydroxytoluene gives a similar result. ${ }^{512}$ The results of these various experiments suggest the particular vulnerability of the reparative cells during $\bar{\partial}$ the mitotic cycle, a factor that assumes some importance in the assessment of lung injury in patients $\stackrel{\varnothing}{\varnothing}$ who are receiving sequential combinations of $\overrightarrow{\overrightarrow{0}}$ antineoplastic drugs, often supplemented by irradia- 3 tion.

Our understanding of the ways in which cells normally communicate with each other is rudi- $\vec{F}$ mentary; even less is known about the mechanisms 을 that control regeneration and repair. The similarities $\underset{x}{\otimes}$ between cellular events in the developing lung and in $\frac{0}{7}$ the repairing lung have been noted and it may be useful to re-examine these relationships. Inductive $ᄋ$ substances synthesised by mesenchymal cells control the serial bifurcation of the bronchial tree,,$^{13}$ and in a ㅇ similar vein a mesenchymal derived peptide which $\triangle$ stimulates differentiation and surfactant secretion by type 2 cells has been identified. ${ }^{14}$

Transfer of messages between cells usually requires close contact and mesenchymal-epithelial communi- $\tilde{O}$ cation during development is dependent upon the for- $\mathbb{N}$ mation of intimate though transient cell junctions. ${ }^{15} \mathrm{O}$ The nature of these contacts between lung cells has 0

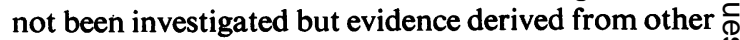
systems suggests they are gap junctions permitting ? passage of nucleotides but excluding larger $\square$ molecules. ${ }^{16}$ Hormonal priming of these junctions may allow passage of chemical messengers across the gap junctions. ${ }^{17}$ The relevance of such observations $\stackrel{\mathbb{Q}}{\mathbb{Q}}$ to the control of orderly regeneration and repair in 
the lung remains to be seen. What is known points to the importance of cell to cell contacts in initiating growth and differentiation and in maintaining a stable milieu. With this in mind we should not be surprised to learn that disintegration of cellular contacts may be followed by disorderly repair with inappropriate secretion of collagen by the cells of the pulmonary interstitium.

Fibrosis results from an imbalance between collagen deposition and removal. In the adult human lung collagen constitutes $15-20 \%$ of the total tissue mass and $60-70 \%$ of all the connective tissue. ${ }^{18}$ In studying the connective tissue content of diseased lungs, biochemists have been surprised to find normal amounts of collagen although the tissue sections show obvious fibrosis. Similarly, the rate of collagen synthesis in cultured explants of these lungs may be normal. Such discrepancies are explained in part by the small size of the biopsy and the possibility that much of the increased interstitial mass observed by the morphologist may not be collagen but an oedematous matrix. ${ }^{19}$ In addition the invariable increase in cellularity, at least in the early phases of repair, emphasises the need to relate collagen mass to measurements of DNA as well as to the dry weight of the lung. In experimental models of pulmonary fibrosis there is without doubt a real increase of collagen ${ }^{18}$ and the conflicting data derived from the lungs of patients with severe restrictive disease are explainable only if one assumes that interstitial pulmonary fibrosis involves not only alterations of quantity but also of the quality, form, and location of collagen. ${ }^{20}$ Such a conclusion is predicated upon the known lability of collagen and on the concept of turnover whereby collagen secretion is usually balanced by collagen resorption.

There is a tendency to regard fibrosis of the lung as a unidirectional process despite a considerable amount of clinical evidence suggesting reversibility. ${ }^{21} 22$ The healing of wounds and fractures depends on an increased production of collagen much of which is resorbed subsequently. Experimental work in these and other systems indicates that collagen breakdown is largely an extracellular event involving increased activity of collagenase. ${ }^{23} 24$ In this process too, cell to cell interactions are essential to the control and modulation of structural remodelling. The dominant effector cells in collagenolysis are fibrobasts and epidermal cells and the chief modulating cells are macrophages. ${ }^{25-27}$

Similar data on collagen remodelling in the lung are not available although a recent paper indicates the continuing presence of collagenase in the alveoli of patients with interstitial pulmonary fibrosis. ${ }^{28}$ The presence of this enzyme is of particular interest because, like the synovial collagenase of rheumatoid arthritis, it is present in the active form. It is not known if it is derived from fibroblasts and epidermal cells or whether it is a product of the reactive granulocytes and macrophages associated with the various types of fibrosing alveolitis.

The demonstration of enzymes such as collagenase in alveolar fluid raises the possibility of using bronchoalveolar lavage for serial investigations of patients with continuing or chronic lung disease. The advantages of such an atraumatic technique over lung biopsy are obvious and one may reasonably expect the cellular and soluble components of the lavage fluid to reflect cellular and humoral activities in the distal respiratory units. Two investigators, Turner-Warwick in London ${ }^{29}$ and Crystal in Bethesda, Md, ${ }^{30}$ have led the way in these investigations. They have defined the normal constituents of the lavaged fluid and described the changes associated with the cryptogenic fibroses. Of particular interest is the distinctive cellular profile of sarcoidosis as compared with other infiltrative diseases of the pulmonary interstitium. More recently, other investigators searching for convenient and reliable markers of lung injury have examined fluids obtained from patients with acute lung injury. ${ }^{31-33}$ Adults with respiratory distress associated with exudative alveolar disease, oedema and hyaline membranes exhibit high levels of elastolytic enzyme activity and low levels of $\alpha_{1}$-antiprotease. The elastase is thought to be derived from neutrophilic leucocytes and the suboptimal levels of antiprotease activity probably results from inactivation by excess elastase or oxidants generated by leucocytes during phagocytosis.

It remains to be seen what clinical benefits emanate from such investigations. For the moment it may be prudent to regard the demonstration of elastase activity in lavage fluid ${ }^{32}$ or elastin derived peptides in the serum ${ }^{34}$ as rather crude and nonspecific indices of tissue damage in the lung; certainly there is no evidence indicating prognostic import to the finding of high or low levels of elastase activity in patients with acute lung injury. ${ }^{32}$ In the meanwhile the search continues for markers of increased sensitivity which would provide the clinician with a quantitative assessment of lung injury. The most promising line of investigation may be the study of the pulmonary endothelium and, in particular, the relationship of endothelial constituents such as factor VIII and its components to the initiation of microvascular injury in the pulmonary circulation.$^{35}$ Such studies, which may be expected to elucidate the early events of acute alveolar injury, may also facilitate the development of markers of greater precision and reliability than any that are presently available.

The past 10 years has seen a surge of research 
activity carrying the investigation of pulmonary diseases beyond descriptive morphology and function, beyond correlations of structure and function to probe the mechanisms of injury and repair. These initial forays into the realm of pulmonary biology have been remarkably successful; pathways of injury have been described and we have acquired a rudimentary knowledge of the interactions of cellular and humoral elements in the control of orderly repair and in the genesis of destructive and fibrotic pulmonary disorders. At best we have defined only the critical questions to be answered. This is no mean achievement and, provided we have identified the appropriate questions, the most difficult problems in pulmonary biology are open to solution.

DRUMMOND H BOWDEN

Department of Pathology

University of Manitoba

Winnipeg, Canada

\section{References}

${ }^{1}$ Shorter RG, Titus JL, Divertie MB. Cell turnover in the respiratory tract. Dis Chest 1964;46:138-42.

2 Weibel ER, Gehr P, Haies D, Gil J, Bachofen M. The cell population of the normal lung. In: Bouhuys A, ed. Lung cells in disease. Amsterdam: Elsevier/ North-Holland Biomedical Press, 1976:3-16.

${ }^{3}$ Crystal RG. The cell population of the normal lung. In: Bouhuys A, ed. Lung cells in disease. Amsterdam: Elsevier/North-Holland Biomedical Press, 1976:17-38.

- Bowden DH, Adamson IYR. Endothelial regeneration as a marker of the differential vascular response in oxygeninduced pulmonary edema. Lab Invest 1974;30:350-7.

- Adamson IYR, Bowden DH, Wyatt JP. A pathway to pulmonary fibrosis: an ultrastructural study of mouse and rat following radiation to the whole body and hemithorax. Am J Pathol 1970;58:481-98.

- Evans MJ, Bils RF. Identification of cells labeled with tritiated thymidine in the pulmonary alveolar walls of the mouse. Am Rev Respir Dis 1969;100:372-8.

' Adamson IYR, Bowden DH. Derivation of type 1 epithelium from type 2 cells in the developing rat lung. Lab Invest $1975 ; 32: 736-45$.

${ }^{8}$ Evans MJ, Stephens RJ, Cabral LJ, Freeman G. Cell renewal in the lungs of rats exposed to low levels of $\mathrm{NO}_{2}$. Arch Environ Hlth 1972;24:180-8.

- Adamson IYR, Bowden DH. The type 2 cell as progenitor of alveolar epithelial regeneration. Lab Invest 1974;30: $35-42$.

${ }^{10}$ Gould VE, Tosco R, Wheelis RF, Gould NS, Kapanci Y. Oxygen pneumonitis in man. Ultrastructural observations on the development of alveolar lesions. Lab Invest 1972;26: 499-508.

11 Adamson IYR, Bowden DH. Pulmonary injury and repair. Organ culture studies of murine lung after oxygen. Arch Pathol Lab Med 1976;100:640-3.

${ }^{12}$ Adamson IYR, Bowden DH, Cote MG, Witschi H. Lung injury induced by butylated hydroxytoluene. Lab Invest 1977;36:26-32.

${ }^{13}$ Dameron F. An experimental study of the organogenesis of the lung: the nature and specificity of the epitheliomesenchymatous interactions. J Embryol Exp Morphol 1968;20:151-67.
${ }^{14}$ Smith BT. Lung maturation in the fetal rat: acceleration by injection of fibroblast-pneumonocyte factor. Science 1979;204:1094-5.

${ }^{15}$ Leung CKH, Adamson IYR, Bowden DH. Uptake of ${ }^{3} \mathrm{H}$ prednisolone by fetal lung explants: role of intercellular contacts in epithelial maturation. Exp Lung Res 1980;1: 111-20.

${ }^{16}$ Pitts JD, Simms JW. Permeability of junctions between animal cells. Exp Cell Res 1977;104:153-63.

${ }^{17}$ Evans WH. Communication between cells. Nature 1980; 283:521-2.

${ }^{18}$ Hance AJ, Crystal RG. The connective tissue of lung. Am Rev Respir Dis 1975;112:657-711.

19 Zapol WM, Trelstad RL, Coffey JW, Tsai I, Salvador RA. Pulmonary fibrosis in severe acute respiratory failure. Am Rev Respir Dis 1979;119:547-54.

${ }^{20}$ Fulmer JD, Bienkowski RS, Cowan MJ et al. Collagen concentration and rates of synthesis in idiopathic pulmonary fibrosis. Am Rev Respir Dis 1980;122:289-301.

${ }^{21}$ Lakshminarayan S, Stanford RE, Petty TL. Prognosis after recovery from adult respiratory distress syndrome. $\mathrm{Am}$ Rev Respir Dis 1976;113:7-16.

${ }^{22}$ Simpson DL, Goodman M, Spector SL, Petty TL. Longterm follow up and bronchial reactivity testing in survivors of the adult respiratory distress syndrome. $A m R C^{\prime}$ v Respir Dis 1978;117:449-54.

${ }^{23}$ Perez-Tamayo R. Collagen resorption in carrageenin granulomas. II. Ultrastructure of collagen resorption. Lab Invest 1970;22:142-59.

${ }^{24}$ Okazaki I, Maruyama K. Collagenase activity in experimental hepatic fibrosis. Nature 1974;252:49-50.

${ }^{25}$ Leibovich SJ, Ross R. A macrophage-dependent factor that stimulates the proliferation of fibroblasts in vitro. Am J Pathol 1976;84:501-14.

${ }^{26}$ Huybrechts-Godin G, Hauser P, Vaes G. Macrophagefibroblast interactions in collagenase production and cartilage degradation. Biochem J 1979;184:643-50.

27 Jimenez SA, McArthur W, Rosenbloom J. Inhibition of collagen synthesis by mononuclear cell supernates. $J$ Exp Med 1979;150:1421-31.

${ }^{28}$ Gadek JE, Kelman JA, Fells G et al. Collagenase in the lower respiratory tract of patients with idiopathic pulmonary fibrosis. $N$ Engl J Med 1979;301:737-42.

29 Haslam PL, Turton CWG, Heard B et al. Bronchoalveolar lavage in pulmonary fibrosis: comparison of cells obtained with lung biopsy and clinical features. Thorax $1980 ; 35: 9-18$.

${ }^{30}$ Hunninghake GW, Gadek JE, Kawanami O, Ferrans VJ, Crystal RG. Inflammatory and immune processes in the human lung in health and disease: evaluation by bronchoalveolar lavage. Am J Pathol 1979;97:149-98.

${ }^{31}$ Orlowski M, Orlowski J, Lesser M, Kilburn KH. Proteolytic enzymes in bronchopulmonary lavage fluids: cathepsin B-like activity and prolyl enchepeptidase. $J$ Lab Clin Med 1981;97:467-76.

${ }^{32}$ Lee CT, Fein AM, Lippmann M, Holtzman H, Kimbel P, Weinbaum G. Elastolytic activity in pulmonary lavage fluid from patients with adult respiratory distress syndrome. N Engl J Med 1981;304:192-6.

${ }^{33}$ Newman RA, Kimberley PJ, Stewart JA, Kelley J. Assessment of bleomycin lung toxicity using angiotensinconverting enzyme in pulmonary lavage. Cancer Res 1980;40:3621-6.

31 Morgan L, Kucich U, Dershaw B et al. Elastin degradation products in the adult respiratory distress syndrome. $\mathrm{Am}$ Rev Respir Dis 1981;123:93.

${ }^{35}$ Carvalho ACA, Bellman S, Saullo J, Lauer J, Zapol WM Altered plasma factor VIII antigen: a sensitive indicator of endothelial damage. Am Rev Respir Dis 1981;123:98. 